\title{
Sistema de Inovação do Paraná: análise do processo de inovação do estado e implicações para política
}

\author{
Aziz Eduardo Calzolaio* \\ Paulo Correia** \\ Ricardo Dathein***
}

\begin{abstract}
Resumo: O objetivo deste trabalho é analisar algumas características importantes do Sistema de Inovação (SI) do Paraná, entre 2006 e 2008. Para tanto, utiliza-se a Pesquisa de Inovação Tecnológica (PINTEC) 2008. São colocados em gráficos os seguintes aspectos das empresas inovadoras do Paraná: importância atribuída às atividades de cooperação; volume de gastos em atividades de inovação; financiamento à inovação e qualificação dos pesquisadores. Os resultados apontam falhas no sistema de inovações paranaense, quais sejam, baixo dinamismo na relação entre Institutos de Ciência e Tecnologia e empresas; quase inexistência de financiamento privado para atividades de inovação; e a insuficiente transferência de pesquisadores pós-graduados das universidades para as firmas. As empresas inovadoras do Paraná caracterizamse como seguidoras das dos países líderes em inovação inédita. Conclui-se que as falhas constatadas neste trabalho devem ser levadas em consideração no momento de definição, implementação e avaliação de políticas de inovação no PR, uma vez que a política de inovação deve ser elaborada conforme a situação específica vivenciada pelas firmas inovadoras e pelo conjunto do SI.
\end{abstract}

Palavras-chave: Sistema de Inovação; Sistema Regional de Inovação; Atividades de Inovação; Política de Inovação.

Classificação JEL: O31; O18.

\footnotetext{
*Doutorando em Ciências Econômicas pela Universidade Federal do Rio Grande do Sul (UFRGS).

** Contador, Economista, Especialista em Economia de empresas, Especialista em Contabilidade gerencial, Mestre em Economia pela UFSC, Doutorando em Economia pela UFRGS, Prof. do Departamento de Economia da UNESPAR/ Apucarana.

***Doutor em Economia, professor associado do Departamento de Economia e Relações Internacionais e do PPGE/ UFRGS. E-mail: ricardo.dathein@ufrgs.br
} 


\section{Introdução}

$\mathrm{Na}$ ciência econômica permeiam diversos pensamentos e abordagens. Todas elas, todavia, concordam que o progresso da Ciência, Tecnologia e Inovação é preponderante para o desenvolvimento econômico. Apesar disso, são escassas informações acerca das potencialidades e limitações dos agentes e instituições envolvidos no processo de inovação. Isso reduz a possibilidade da política de inovação auxiliar de forma mais intensa o processo de inovação das empresas (Carvalho, 2010), o que, por consequência, atenua o potencial aumento da competitividade e da produtividade das firmas.

$\mathrm{Na}$ tentativa de superar tais escassezes, surgiram diversos modelos relacionando Ciência, Tecnologia, Inovação e Sociedade. Todos eles com ênfase na interação dos vários atores que se articularem no processo de geração de novos produtos e processos. Os principais modelos são: Modo 1 e Modo 2; Hélice Tripla; Construção Social da Tecnologia; Teoria do Ator-Rede; e Sistema Nacional de Inovação (SNI) (Velho, 2011). Merece destaque este último. Ele inclui, dentre suas abordagens, uma que se denomina Sistema Regional de Inovação (SRI), a qual é adequada para analisar o Sistema de Inovação (SI) do estado do Paraná (PR).

As regiões possuem diferenças em suas estruturas econômicas e sociais. Muito mais, a capacidade de inovação das empresas depende do nível de formação de clusters, da dotação institucional local e da intensidade com que os agentes regionalizados interagem entre si (Tödtling e Trippl, 2005). É preciso considerar, ainda, a extensão do spillover de conhecimento dentro de um determinado espaço geográfico.

O desenvolvimento das capacitações e rotinas das firmas depende do ambiente local onde elas atuam, pois em cada área, as redes de interação e o seu conhecimento interno desenham-se de forma peculiar. Isso interfere na habilidade de inovação das firmas. Assim, cada região possui diferenças em termos de sua indústria, instituições e conhecimento, diferindo em potencialidades e problemas econômicos (Tödtling e Trippl, 2005).

Porém, a defasagem de informações e dados detalhados acerca dos SRIs restringe o potencial da política de inovação. Esta acaba tendo como referência as práticas e as tradições do passado, ao invés de estudos analíticos (Carvalho, 2010). Nesse caso, sua formulação ocorre sem um diagnóstico preciso do problema a ser superado. Assim, suas medidas podem não ser as mais eficazes para superar as reais dificuldades. Em isso ocorrendo, desperdiçam-se oportunidades de fomentar de forma eficiente a inovação das empresas. Assim, para melhorar os resultados da política de inovação, necessita-se de maiores esclarecimentos em relação aos mecanismos que culminam na inovação e sua difusão (Velho, 2010).

A abordagem do SI sugere que a política seja elaborada conforme a situação específica vivenciada pelo conjunto do SI (Edquist, 2001; Metcalfe e Gorghiou, 1997). Por isso, o policy maker, acima de tudo, deve conhecer a situação do SI alvo de incentivo, identificando barreiras que dificultam as inovações e, 
então, propor políticas. Desse modo, estabelecer uma política de inovação é um processo dinâmico e exige o conhecimento específico do SI em questão. Isso favorece, caso a caso, aplicar o instrumento político mais adequado.

A política de inovação do PR precisa embasar suas decisões em estudos que coletem informações e produzam estatísticas acerca dos processos de inovação desse estado. Assim, dados dos agentes e instituições envolvidas no processo de inovação paranaense são cruciais. Por isso, este artigo analisa alguns aspectos do SRI do Paraná. Contribui para a compreensão de alguns elementos indispensáveis à inovação regional, tais como: importância atribuída às atividades de cooperação; volume de gastos em atividades de inovação; financiamento à inovação e qualificação dos pesquisadores.

O objetivo deste trabalho é analisar algumas características importantes do SI do Paraná, entre 2006 e 2008. Para tanto, utiliza-se a Pesquisa de Inovação Tecnológica (PINTEC) 2008, elaborada pelo Instituto Brasileiro de Geografia e Estatística (IBGE). O estudo coloca de forma simples - através de gráficos - e clara, os seguintes aspectos das empresas inovadoras ${ }^{1}$ do Paraná: impacto da inovação sobre a venda e competitividade das firmas; grau de novidade dos produtos lançados; grau de importância das atividades de inovação. Além dessas, também coloca aspectos como as fontes de informações e da cooperação mais importantes; valores despendidos no processo de inovação; fonte de financiamento à inovação; e qualificação dos pesquisadores que atuam nas firmas. Tais elementos são indispensáveis à elaboração de políticas mais eficazes.

Após esta introdução, a segunda seção faz uma breve revisão da literatura acerca do SRI. Em seguida, a terceira seção analisa parte do processo de inovação das empresas do PR, identificando falhas no SI desse estado. Por fim, encerra-se com as considerações finais na seção quatro.

\section{Revisão da Literatura - Sistema Regional de Inovação}

Segundo Edquist (1997), SI é um conjunto importante de elementos econômicos, sociais, políticos, organizacionais e institucionais. Todos esses aspectos influenciam o desenvolvimento, a difusão e o uso de inovações. É da relação entre esses diversos fatores que se desenha o modo pelo qual o financiamento, aprendizado e conhecimento, qualificação profissional, relações institucionais, entre outros, ocorreram em um país ou região. Portanto, é necessário entender a relação entre as organizações e instituições que compõem um SI, identificando o papel de cada um deles.

A abordagem do sistema de inovação teve forte impulso nos trabalhos de Freeman (1995). Este esclareceu que, apesar do processo de globalização, os sistemas nacionais e regionais de inovação são essenciais na análise econômica

\footnotetext{
1 A definição de inovação adotada neste trabalho é a utilizada pelo IBGE, baseada no Manual de Oslo, que a define como "introdução, no mercado, de um produto (bem ou serviço) novo ou substancialmente aprimorado, ou introdução, na empresa, de um processo produtivo novo ou substancialmente aprimorado" (PINTEC, 2008, p. 152). Destaca-se que é inovação o produto e/ou processo novo (ou substancialmente aprimorado) lançado pela ou na empresa, mesmo que no mercado/setor de sua atuação ele já exista.
} 
das mudanças tecnológicas, uma vez que as firmas dependem das características do ambiente interno de seu país para produzirem inovações. "Whilst external international connecting are certainly of growing imponance, the influence of the national educational system, industrial relations technical e scientific institutions, government policies, cultural, traditions and many other national institutions is fundamental' Freeman (1995, p. 5).

Tanto Breschi e Malerba (1997) quanto Edquist (2004) destacaram dois conceitos sobre Sistemas de Inovação: i) SNI - tratando da análise das interações dos agentes ${ }^{2}$ que geram e difundem a inovação. Essa abordagem delimita o aspecto geográfico do SI em âmbito nacional. Ela utiliza como critério para essa delimitação a língua, cultura, história de instituições sociais e políticas de um povo. ii) Sistemas Tecnológicos (STs), definidos como uma rede de agentes, interagindo em uma área econômica e industrial específica sobre uma infraestrutura institucional particular. STs são, portanto, relacionados às tecnologias e indústrias de uma particular localidade. Assim, os diferentes efeitos da inovação, dependem do limite territorial em que a inovação se processa. Isso possibilita formar conceitos ligados aos Sistemas Regionais ou Locais de Inovação.

A região é um fator que interfere na inovação. O papel do ambiente local vai além da simples recepção de processos técnicos elaborados externamente. Assume uma função ativa na sustentação das redes de empresas, responsáveis pela dinâmica das inovações (Freeman, 1995; Lundvall, 2003). Narula e Dunning (2009) explicam que os territórios são muito mais do que pura base física para indivíduos e empresas. São, na verdade, uma teia de relações sociais que estabelecem regras e promovem a confiança entre os atores.

A abordagem do SRI considera importante para o processo de inovação tanto os fatores de aprendizado e conhecimento das firmas, quanto os fatores históricos de uma região. Além disso, inclui como relevantes as instituições e as interações dos diversos agentes econômicos.

O SRI valoriza as peculiaridades sociopolíticas da localidade de atuação. Ele abrange uma significativa diversidade de processos históricos, desenhos políticos/institucionais, culturais, educacionais e geográficos presentes nas regiões (Edquist, 2004). No mesmo sentido, Albagli e Britto (2002) destacam que a geração da capacidade inovativa nasce da confluência de fatores sociais, institucionais e culturais particulares. Esses fatores são aqueles que circundam os atores econômicos inseridos em determinada área.

Segundo Lundvall (2003) e Negri et. al. (2005), as principais características comuns dos SRIs passam pelos seguintes pontos: i) os sistemas locais são originados a partir da especialização de um produto ou de uma atividade principal (core activity), ou seja, cada região difere em relação ao seu padrão de especialização industrial (Tödtling e Trippl, 2005); ii) as técnicas e produtos tendem a ser confeccionados a partir de conhecimentos adquiridos e desenvolvidos regionalmente; iii) as atividades locais desenvolvidas tendem a se concentrar em pequenas e médias unidades produtivas, embora abriguem

2 Os principais agentes são: firmas, universidades, escolas profissionalizantes, institutos de pesquisa e governo). 
empresas de maior porte; iv) há forte presença de um conjunto de firmas interdependentes, o que tende a facilitar os fluxos de informações repassadas, resultando na formação de redes produtivas e de inovação; v) os sistemas produtivos locais tendem a manter maior integração internacional; e, vi) a presença de relações dentro de um contexto histórico e social específico culmina em fortes relações fundamentadas na confiança mútua entre os atores do sistema.

Tödtling e Trippl (2005) destacam, ainda, dois pontos que justificam a premência da abordagem regional. Segundo esses autores, o spillover do conhecimento é limitado a uma região e o conhecimento tácito necessita de contato pessoal para ser transferido. Portanto, a proximidade geográfica facilita sua troca.

Nas regiões dinâmicas em inovação, configura-se densa rede de relações entre empresas que interagem fornecendo bens e serviços uma para outra, assim como fortes interações entre iniciativas empresariais, organizações públicas e associações diversas da comunidade civil. Essas veementes relações e interações melhoram a competitividade e o processo de inovação.

Para formular políticas de inovação, sugere-se descobrir os problemas encontrados em um SI que impedem o desenvolvimento da inovação no setor privado (Edquist, 2001). Ao tratar-se de um estado, é necessário encontrar os obstáculos do SRI para, assim, contorná-los. Em se fazendo isso, encontra-se um conjunto de "Falhas do Sistema de Inovação" (System failures, segundo Edquist, 2001) - dificuldades que impedem a inovação e podem ser superadas com o auxílio de políticas adequadas.

Metcalfe e Gorghiou (1997) corroboram a ideia das "Falhas do Sistema de Inovação" ao explicar que a política será elaborada conforme a situação específica vivenciada pelas firmas inovadoras e pelo conjunto do SI. Assim, é função do policy maker paranaense analisar a situação do SRI. Nessa averiguação, devemse identificar os obstáculos que bloqueiam a fluidez da inovação e, então, propor políticas que atinjam o cerne do problema. Para contribuir com esse processo, a próxima seção apresenta algumas características do SI paranaense.

\section{Procedimentos Metodológicos - Inovação nas empresas do Paraná}

Os dados apresentados a seguir foram extraídos da PINTEC 2008, lançada em $2010^{3}$ e realizada pelo Instituto Brasileiro de Geografia e Estatística - IBGE. Essa pesquisa fornece indicadores aprofundados das atividades de inovação tecnológicas nas empresas brasileiras, utilizando uma metodologia que permite comparações internacionais.

Os dados da PINTEC são de dois tipos, qualitativos e quantitativos. O primeiro não envolve registro de valor, revelando a visão da empresa em relação ao seu próprio processo de inovação. Em outras palavras, aponta a opinião

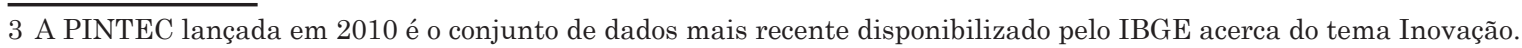


que a empresa possui das suas atividades de inovação. Abrange, geralmente, um período de três anos consecutivos, sendo que neste trabalho esses dados se referem ao período de 2006 a 2008. O segundo agrega medidas acerca da inovação das firmas. Os dados referentes a valores gastos em atividades de inovação referem-se ao último ano da pesquisa, no caso 2008.

Em seguida, apresentam-se os dados da PINTEC 2008 especificamente para o estado do Paraná. A intenção é revelar algumas dimensões regionais da inovação das empresas paranaenses. Para tanto, informações qualitativas e quantitativas das firmas inovadoras do Paraná são explicitadas adiante.

O universo das Empresas Inovadoras do Paraná (EIPR) inclui aquelas que: localizavam-se no PR no momento em que o questionário da PINTEC 2008 foi aplicado; estavam em situação ativa no Cadastro Central de Empresas (CEMPRE); atuavam nas indústrias extrativas e de transformação; tinham dez ou mais pessoas ocupadas; e implementaram produto e/ou processo novo.

Os dados das EIPR contemplam informações relacionadas às atividades ex ante a finalização do produto ou processo novo, bem como as que dizem respeito aos impactos que a inovação causou após serem lançadas no mercado. Pesquisase o impacto causado pela inovação sobre a venda das empresas; a importância das atividades de inovação, bem como o volume gasto nas mesmas; a fonte dos recursos aplicados no processo de inovação; e a qualificação dos pesquisadores contratados pelas firmas.

A PINTEC registrou, entre 2006 e 2008, 8.974 empresas industriais no PR, das quais 3.939 implementaram produto e/ou processo novo ou substancialmente aprimorado. Este número representa 43,8\% das empresas do estado. Ao considerar o número de empresas que inovaram no Brasil, 38,1\%, verifica-se que a intensidade de inovação no Paraná é maior do que no resto do país.

As inovações são importantes para a manutenção da competitividade e, assim, para as empresas paranaenses manterem-se no mercado, além de garantir uma parcela significativa das firmas desse estado. No período de 2006 a 2008, um total de 3.939 empresas $^{4}$ realizaram inovações, sendo que 2.494 inovaram em produto e 3.343 inovaram em processo. No caso das inovações de produto, constata-se que $42 \%$ dos produtos novos são responsáveis por mais de 40\% das vendas de 1.035 empresas que inovaram; 40\% dos produtos novos são responsáveis por entre 10\% e 40\% das vendas de 392 empresas que inovaram; e apenas $19 \%$ dos produtos novos são responsáveis por menos de $10 \%$ das vendas de 466 empresas que inovaram.

4 Essas 3.939 empresas que implementaram produto e/ou processo novo são chamadas neste trabalho de Empresas Inovadoras do PR (EIPR). 


\section{Gráfico 1 - Participação dos produtos novos ou substancialmente aprimorados no total das vendas internas em 2008}

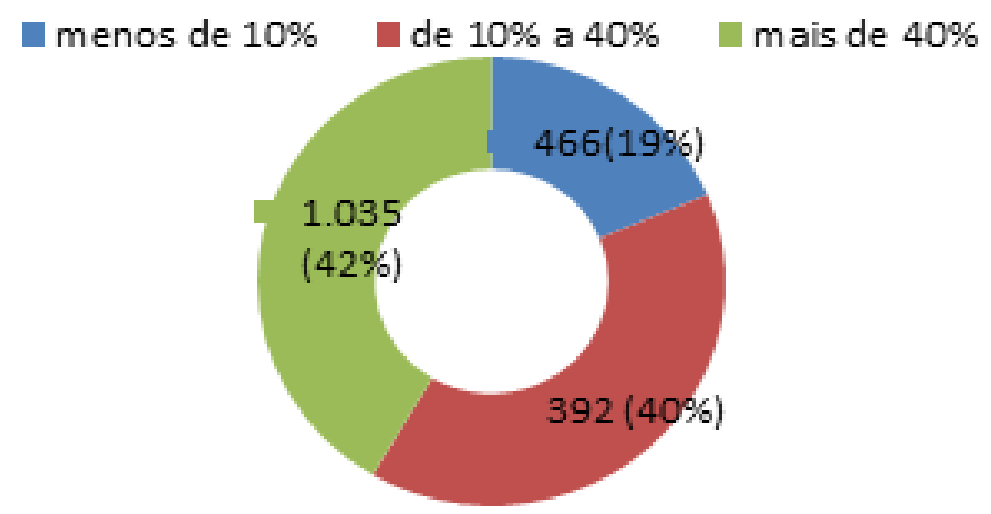

Fonte: Elaboração própria a partir da PINTEC 2008

No entanto, a dinâmica de inovação das empresas do PR revela-se em pequena capacidade de lançar produtos e processos inéditos para o Brasil e o mundo. Isso é evidenciado pelo grau de novidades das inovações lançados pelas EIPR. O gráfico 2 revela que $85 \%$ dos produtos novos são originais apenas para as empresas, que antes não os produziam e, então, passam a produzi-los, disseminando produtos já existentes. Para o mercado mundial, foram novos apenas 74 produtos em três anos. Em relação aos processos inovativos, o gráfico 3 demonstra que $93 \%$ desses processos foram novos para as empresas, mas não para o setor. Novos para o setor, em termos mundiais, foram apenas 4 processos entre 2006 e 2008.

\section{Gráfico 2 - Grau de novidade do principal produto inovador das EIRS - 2006 a 2008}
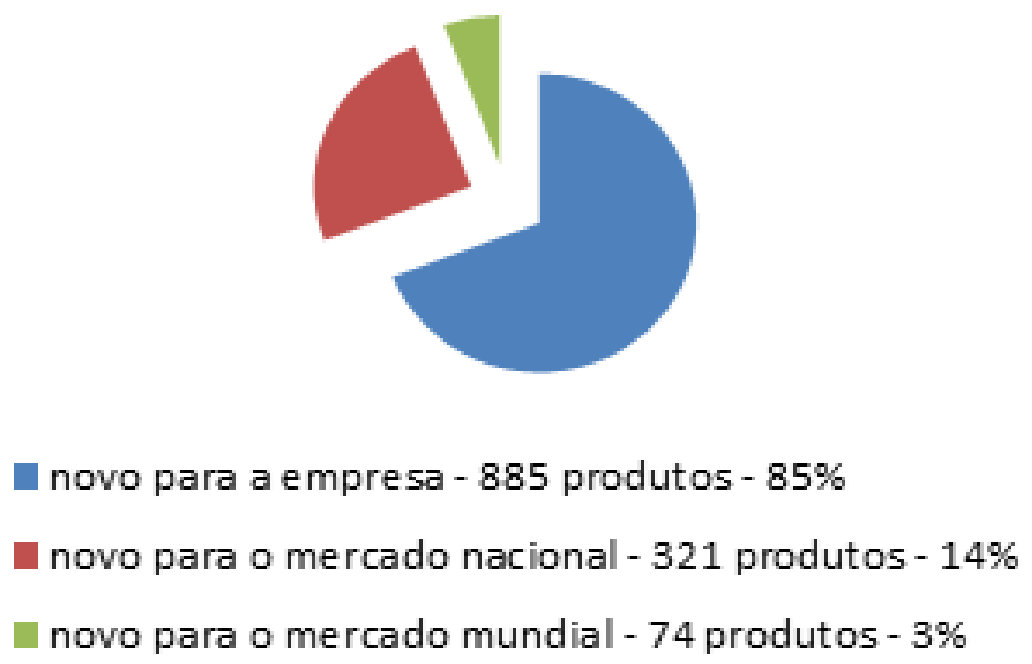

Fonte: Elaboração própria a partir da PINTEC 2008. 


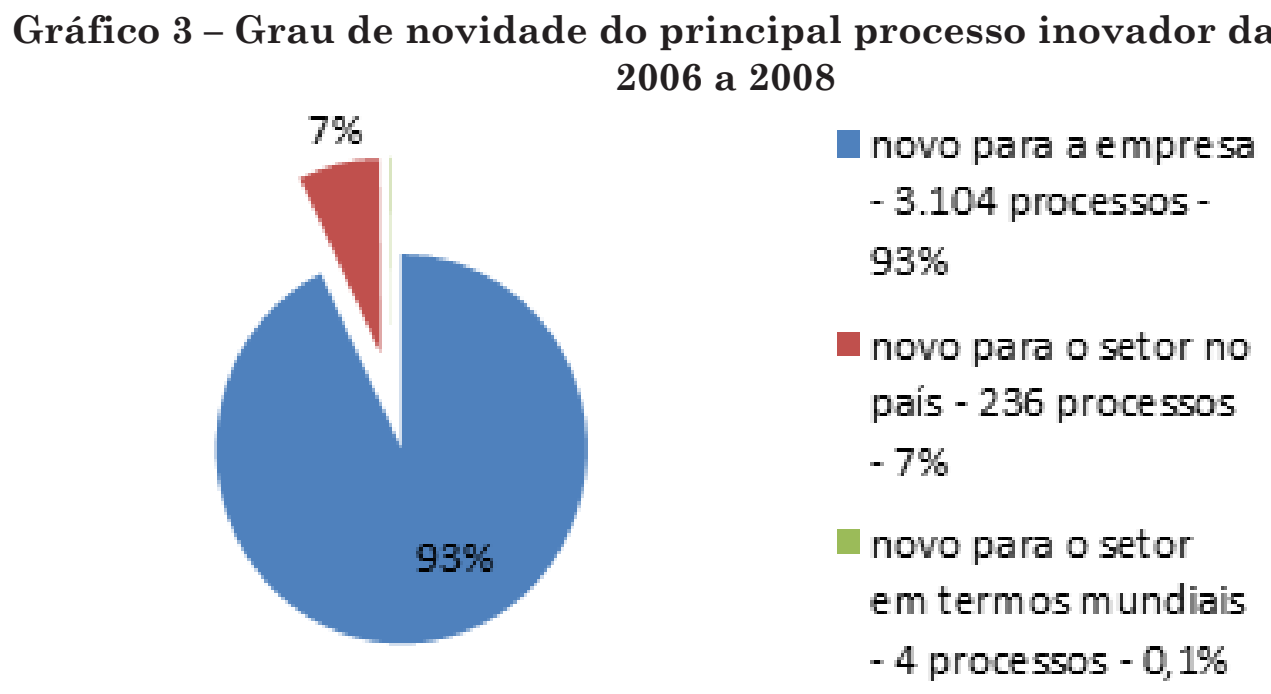

Fonte: Elaboração própria a partir da PINTEC 2008.

\subsection{Resultados - A percepção subjetiva das empresas inovadoras do PR}

Apesar da importância financeira das inovações, as firmas do PR encontram-se defasadas no seu processo de inovação. Isso é constatado na sequência de análise que enfoca a percepção que os dirigentes da indústria paranaense possuíram, entre 2006 e 2008, em relação às diversas atividades de inovação.

O gráfico 4 informa o percentual de empresas que atribuíram alto grau de importância para cada uma das atividades de inovação listadas. Constata-se que apenas $2 \%$ das empresas acreditavam que a aquisição externa de P\&D possuía alto grau de importância para a inovação. Também poucas empresas, 7\%, concordaram que a aquisição de outros conhecimentos externos era de grande relevância. Ainda baixo, 9\% das empresas expressaram grande interesse pelo P\&D interno. Uma proporção pouco maior de empresas, 14\%, declarou que a introdução das inovações no mercado era fundamental. Já projeto industrial e outras preparações técnicas eram proeminentes para $24 \%$ das empresas. As atividades de inovação mais valorizadas foram treinamento e aquisição de máquinas e equipamentos. Estas possuíam alta importância para, respectivamente, $47 \%$ e $65 \%$ das EIPR. Portanto, destaca-se a declaração das firmas de que compras de máquinas e equipamentos são a fonte mais importante para inovar, enquanto conhecimento e P\&D externo estão nas últimas posições. 
Gráfico 4 - Percentual de empresas inovadoras do PR que atribuíram alta importância para as respectivas atividades de inovação entre 2006 e 2008

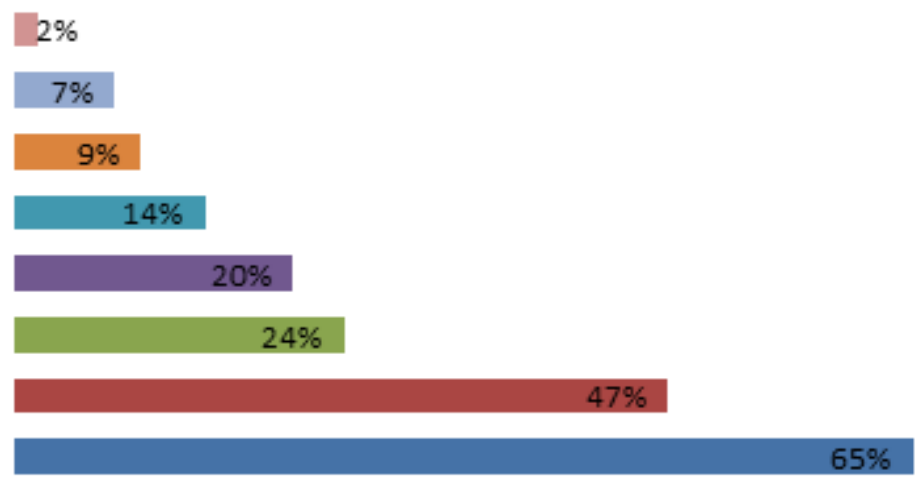

Fonte: Elaboração própria a partir da PINTEC 2008

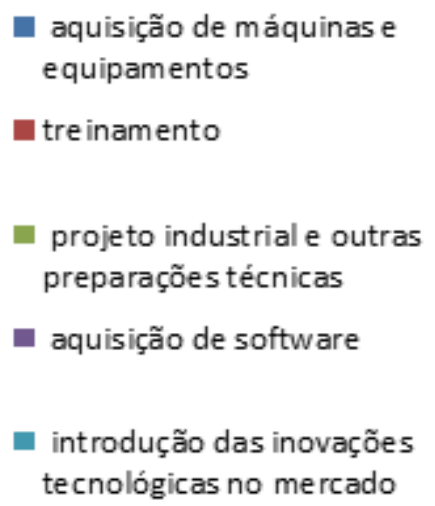

A classificação segundo as origens de informações requeridas para inovar é dada no gráfico 5. Este expressa o percentual de empresas que atribuíram alta importância, de acordo com a fonte de informação. Destaca-se o baixo número de empresas que manifestam elevado interesse pelas informações advindas das universidades e institutos de pesquisa, centros tecnológicos, e departamento de P\&D, respectivamente $5 \%, 4 \%$ e $7 \%$. Por outro lado, as informações advindas da internet, clientes ou consumidores, e fornecedores são vistas como valiosas por, respectivamente, por $48 \%, 44 \%$ e $28 \%$ das empresas.

\section{Gráfico 5 - Percentual de empresas inovadoras do RS que atribuíram alta importância para informações segundo sua origem entre 2006 e 2008}

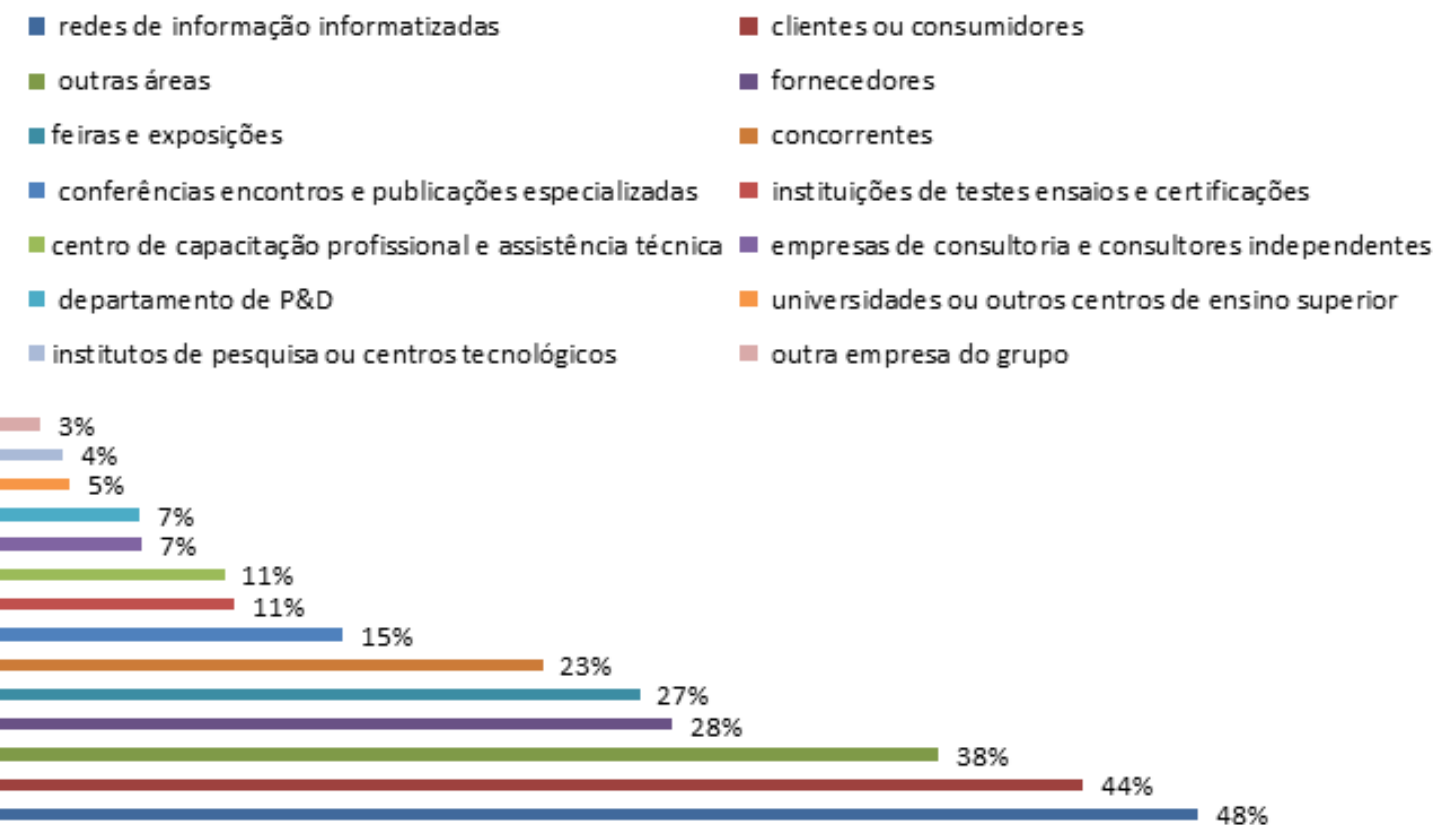

Fonte: Elaboração própria a partir da PINTEC 2008. 
Verifica-se, no gráfico 6, como a cooperação com vistas à inovação é avaliada pelas empresas. Apenas 426 empresas, das 3.939 EIPR, efetuaram cooperações com alguma das organizações listadas no gráfico.

De um lado, verifica-se que apenas $1 \%$ das EIPR aposta no alto grau de importância da cooperação com universidades. Além disso, apenas $0,6 \%$ estimaram como relevante a cooperação entre empresas. Por outro lado, os clientes são considerados a principal fonte para parcerias na elaboração de novos produtos, eleita por $4 \%$ das empresas. A segunda fonte mais relevante são os fornecedores, $3,9 \%$ das firmas salientam que eles são parceiros importantes.

\section{Gráfico 6 - Percentual de empresas inovadoras do PR que atribuíram alto grau de importância para a cooperação com as respectivas organizações entre 2006 e 2008}
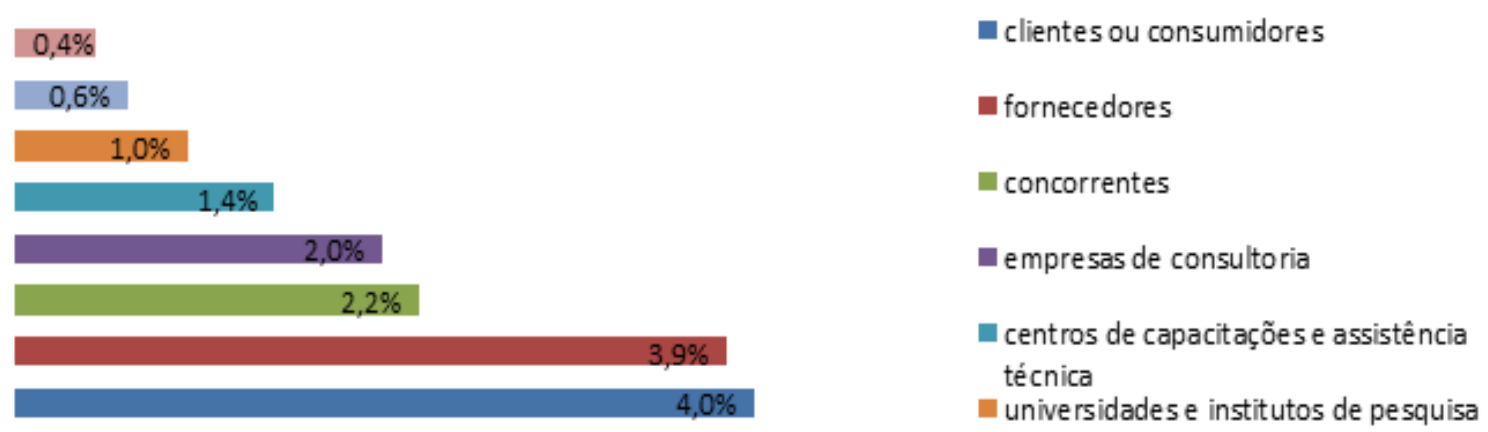

Fonte: Elaboração própria a partir da PINTEC 2008.

Os três gráficos anteriores demonstram indícios acerca da fragilidade do SI paranaense, apontando baixo dinamismo nas relações entre importantes agentes de um SI: empresas, universidades e Institutos de Ciências e Tecnologia (ICTs). Ao mesmo tempo, as empresas embasam seu processo de inovação em aquisição e uso de máquinas e equipamentos, dando pouca ênfase ao conhecimento e à $\mathrm{P} \& \mathrm{D}$, aproximando-se pouco de universidades.

\subsection{Análise quantitativa da inovação nas empresas inovadoras do $P R$}

A PINTEC 2008 aponta que 3.939 empresas industriais no PR realizaram inovações de produtos e/ou processo entre 2006 e 2008. Elas gastaram em atividades de inovação, o valor total de $\mathrm{R} \$ 2,272$ bilhões (em 2008). Esse número representa $0,04 \%$ dos gastos em atividades de inovação feitas por todas as empresas inovadoras brasileiras. A receita das EIPR foi de quase $\mathrm{R} \$ 108,805$ bilhões em valores correntes de 2008. Já o número de empresas que realizaram $\mathrm{P} \& \mathrm{D}$ foi de 405 , investindo nessa atividade $\mathrm{R} \$ 422$ milhões.

A Tabela 1 expõe as diversas atividades de inovação que foram realizadas pelas EIPR. A categoria de maior importância é a compra de máquinas e equipamentos ${ }^{5}$, seguida de gastos em P\&D interno. Cabe ressaltar que o

5 Consideram-se apenas máquinas, equipamentos e hardware, utilizados especificamente para a implementação de produtos ou processos novos ou aperfeiçoados. 
gasto em P\&D interno é quase quatro vezes menor do que o com aquisição de máquinas e equipamentos. Os dados demonstram que o gasto com aquisição de máquinas e equipamentos corresponde a $62,0 \%$ dos gastos totais em atividades de inovação das empresas. Esse número é bem maior do que os 17,1\% voltados para o P\&D interno, bem como do valor dispensado à aquisição de $\mathrm{P} \& \mathrm{D}$ externo, que é inferior a $1,0 \%$ dos gastos totais.

Proporcionalmente à receita líquida de vendas, as despesas com aquisição de máquinas e equipamentos equivalem a quase $1,4 \%$ da receita das empresas, sendo que o gasto com P\&D interno aproxima-se de $0,4 \%$ do faturamento. Além disso, é possível confirmar o pífio relacionamento comercial entre setor privado e instituições externas produtoras de conhecimento e P\&D. Isso é mais uma vez constatado pelos gastos destinados à comercialização com outras instituições. Veja que aquisição de outros conhecimentos e de $\mathrm{P} \& \mathrm{D}$ externo não representam nem $0,1 \%$ das receitas das empresas.

Conclui-se que a aquisição de conhecimentos e P\&D externos são consideradas atividades de menor importância para as empresas. Isso é atestado tanto pelos dados qualitativos quanto pelos quantitativos ora apresentados. Aqueles dados são corroborados por estes. Ambos sinalizam a baixa interação entre as empresas com universidades e ICTs. Foi confirmado que a aquisição de P\&D e de conhecimento externo são as atividades de inovação em que as empresas menos investem. Portanto, não somente poucas empresas atribuíram importância relevante ao conhecimento e ao P\&D externo, mas também foram nessas atividades que menos se investiu. Com isso, os laços entre empresas e ICTs ficam fragilizados, enfraquecendo uma das relações mais importantes de um SI.

Tabela 1 - Atividades de inovação de empresas inovadoras do PR: número de empresas, valor realizado e proporção sobre receitas líquidas de vendas em 2008

\begin{tabular}{|c|c|c|c|}
\hline Atividades de inovação & $\begin{array}{l}\text { Número de } \\
\text { empresas }\end{array}$ & $\begin{array}{l}\text { Valor corrente } \\
(\mathrm{R} \$ \text { mil })\end{array}$ & $\begin{array}{l}\text { Proporção sobre receitas } \\
\text { líquidas de vendas }\end{array}$ \\
\hline $\begin{array}{l}\text { Aquisição de máquinas e } \\
\text { equipamentos }\end{array}$ & 2324 & 1240381 & $1,14 \%$ \\
\hline Atividades internas de $\mathrm{P} \& \mathrm{D}$ & 405 & 422817 & $0,39 \%$ \\
\hline $\begin{array}{l}\text { Introdução das inovações } \\
\text { tecnológicas no mercado }\end{array}$ & 891 & 244341 & $0,22 \%$ \\
\hline $\begin{array}{l}\text { Projetos industriais e outras } \\
\text { preparaçôes técnicas }\end{array}$ & 1051 & 155403 & $0,14 \%$ \\
\hline Aquisição de software & 882 & 71213 & $0,07 \%$ \\
\hline Treinamento & 1177 & 50990 & $0,05 \%$ \\
\hline $\begin{array}{c}\text { Aquisição de outros } \\
\text { conhecimentos externos }\end{array}$ & 372 & 48.402 & $0,04 \%$ \\
\hline Aquisição externa de P\&D & 104 & 39294 & $0,036 \%$ \\
\hline
\end{tabular}

Fonte: Elaboração própria a partir da PINTEC 2008. 
Por outro lado, um terceiro elemento no SI, de grande importância, é analisado no estado do Paraná. Trata-se do financiamento privado à inovação nas empresas. $\mathrm{O}$ gráfico 7 apresenta as fontes de financiamento das atividades de inovação das empresas paranaenses. As origens dos recursos podem ser a própria poupança da empresa ou recursos de terceiros, que se subdividem em privados ou públicos.

Verifica-se que 90\% dos valores dispêndios com P\&D foram financiados por recursos próprios, enquanto 10\% foram financiadas com recursos de terceiros. Observa-se que o governo é responsável por financiar integralmente os recursos buscados externamente. O financiamento das demais atividades de inovação ocorreu, em $71 \%$ dos casos, com recursos próprios e, em 29\%, com recursos de terceiros, dos quais o setor privado participou com $7 \%$ e o setor público com $22 \%$. Assim, as instituições financeiras do SI do Paraná são debilitadas, já que poucas instituições financiam o processo de inovação das firmas. E quando isso acontece, o governo é o maior agente credor. Esse traço é também uma característica marcante na estrutura de financiamento das atividades de inovação de empresas brasileiras, que utilizam predominantemente recursos próprios (Luna, Moreira e Gonçalves, 2008).

\section{Gráfico 7 - Fontes de financiamento das atividades de P\&D e das demais atividades inovativas das empresas inovadoras do PR - em \%}

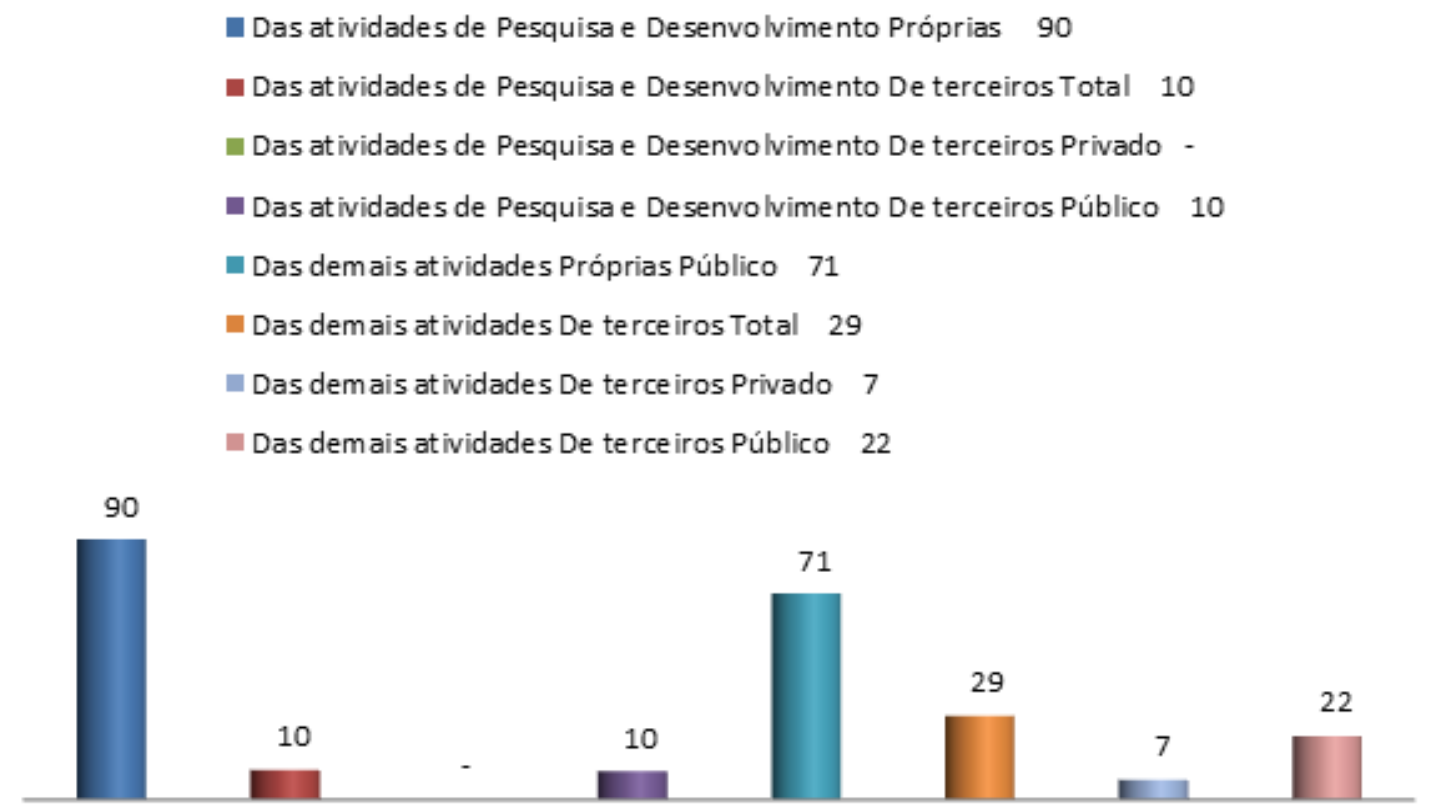

Fonte: Elaboração própria a partir da PINTEC 2008

Em relação à alocação dos recursos públicos destinados à inovação, 1.030 empresas receberam aportes do governo. Isso significa $26 \%$ das empresas inovadoras do PR. Beneficiaram-se com incentivos fiscais 42 empresas. A subvenção econômica foi concedida para 68 empresas. Já o financiamento para projetos de pesquisas e inovações tecnológicas destinou-se para 62. As outras políticas de inovação apoiaram 341 empresas. Porém, a grande maioria das 
firmas, 607, usaram as políticas públicas para financiar máquina e equipamento disseminador de inovações. Isso é um indício de que a política pública está sendo utilizada para manter o padrão de disseminação de inovações já existentes em outros mercados mundiais.

Verifica-se que o SI do PR é limitado pela falta de financiamento privado à atividade de inovação. Isso pode ser um vestígio da pouca disposição, tanto por parte da empresa quanto dos financiadores particulares, de envolver-se em uma atividade de risco: a inovação.

$\mathrm{Na}$ sequência de análise das EIPR, investigam-se os recursos humanos dedicados às atividades de inovação. Estavam empregadas 3.391 pessoas nas atividades de P\&D das EIPR em 2008. Isso representou apenas 0,006\% do total de pessoas ocupadas nessas firmas. Esses funcionários estavam divididos entre as seguintes qualificações: 19\% possuíam nível médio, $72 \%$ graduação, apenas $6 \%$ tinham pós-graduação, e 3\% tinham outros níveis escolares não especificados ${ }^{6}$, conforme o gráfico 8.

\section{Gráfico 8 - Percentual de pessoas ocupadas nas atividades internas de P\&D das empresas do PR que implementaram inovações, por nível de qualificação, em 2008}

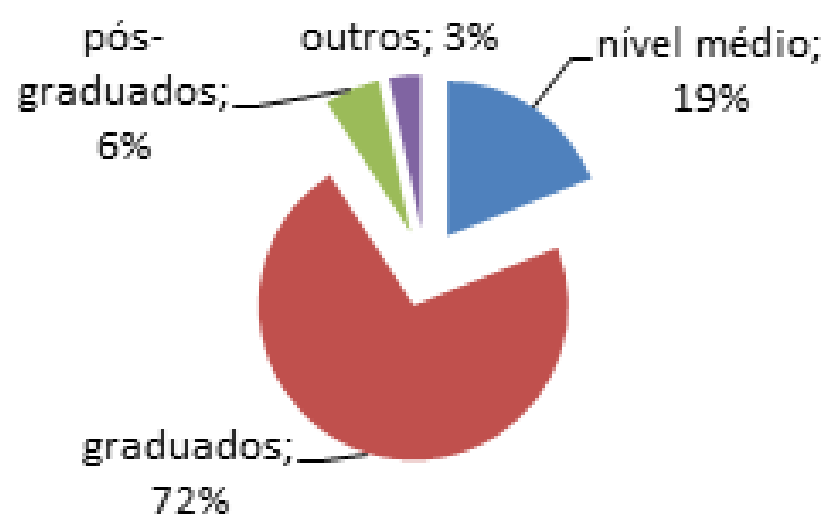

Fonte: Elaboração própria a partir da PINTEC 2008

Esses dados acerca da mão de obra evidenciam um limite para a produção de P\&D nas empresas, ou seja, a falta de qualificação profissional. Em sua grande maioria, os funcionários não possuem conhecimento para manejar técnicas avançadas nas diversas áreas do conhecimento. Isso restringe o uso de laboratórios de P\&D e seus equipamentos com o máximo de proveito. Portanto, a falha na relação entre universidades e empresas não ocorre apenas na transmissão de conhecimento, mas também pela falta de transferência de mão de obra qualificada daquelas para estas.

\subsection{Breve apontamento das Falhas do Sistema de Inovações do PR}

6 A título de comparação, nota-se que no RS, a qualificação dos pesquisadores, também segundo a PINTEC 2008, compõe-se por 35,9\% com ensino médio e 33,4\% com graduação (CALZOLAIO, ZEN e DATHEN, 2012). 
Esta seção resume e interpreta as informações acerca do SI paranaense, apontadas anteriormente. De início, verificou-se que a inovação possui um peso importante para a competitividade e receita das empresas paranaenses. Todavia, cerca de $85 \%$ dos produtos e 93\% dos processos lançados, entre 2006 e 2008 , foram inovações apenas para a própria empresa, sendo já conhecidas pelo mercado. Logo, nesse estado houve poucas inovações inéditas. Suas empresas seguem os lançamentos de inovações das economias avançadas.

O padrão seguidor de inovações é caracterizado por firmas que compram máquinas modernas com capacidade de produzir e disseminar produtos lançados pelas empresas dos países líderes. No Paraná, a compra de máquinas e equipamentos é a atividade de inovação mais preferida pelas empresas. Já a $P \& D$ e a aquisição de conhecimento externo quase não tem importância para elas.

A abordagem teórica adotada neste trabalho confirma a importância de redes locais de firmas, além de apontar que a dinâmica em inovação se configura em uma densa rede de relações entre empresas. Todavia, essa densa rede relacional de firma é fraca no estado do Paraná, já que foi constatado que a troca de informações entre as firmas é a última opção em termos de fontes de informações para a inovação entre as EIPR.

No mesmo sentido, as instituições de pesquisa, ciência e tecnologia, bem como as universidades e centros de ensino superior, estão, respectivamente, na $13^{\circ}$ e $12^{\circ}$ posição enquanto fonte de informação para inovação das firmas. O SI paranaense é marcado por um distanciamento entre empresas e centros universitários. Isso é um grande problema na era em que o conhecimento tornase, cada vez mais, a base do desenvolvimento econômico.

A quase inexistência de financiamento privado à inovação é outra falha do SI paranaense. A demanda de garantias para concessão de financiamento e o risco associado à inovação são fatores que contribuem para esta situação. Além do uso de recursos próprios pelas empresas, o estado contribuiu para atenuar essa falha, alocando recursos públicos.

Por fim, foi verificado que os pesquisadores na área de P\&D das empresas possuem um grau de qualificação de nível superior considerável, o que é positivo. Mas ao mesmo tempo, é uma afirmação do padrão de inovação seguidor de países avançados, pois é preciso certo nível de conhecimento para que as tecnologias vindas desses países adaptem-se às necessidades e exigências locais. Com isso, consegue-se modificar, ainda que de forma elementar, a tecnologia importada. Nesse processo são necessários engenheiros e técnicos com certo grau de conhecimento.

O padrão seguidor de inovação resulta em baixo potencial relativo do desenvolvimento das capacitações e conhecimentos das firmas, imprescindíveis na produção de inovações. Consequentemente, a empresa não se diferencia, dificultando a geração de um ambiente competitivo sistêmico, propício para se ganhar mercado nacional e internacional e, por fim, gerar crescimento econômico. Dessa forma, é papel da política de inovação contribuir para a modificação desse quadro, admitindo-se as dificuldades inerentes a um quadro estrutural não 
propício ao processo de geração de inovações.

Além disso, as políticas necessitam de avaliações para aferirem seus impactos. Isso envolve analisá-las, comparando-as com as praticadas em outros estados e países, e construir indicadores de seu impacto sobre as inovações.

O SI é uma rede complexa de agentes e instituições. Este trabalho limitou-

se a conhecer pequena parte do SI paranaense. É necessário, portanto, outras análises focando nos seguintes aspectos: padrão de especialização industrial do Paraná - core activity (Tödtling e Trippl, 2005); técnicas e produtos confeccionados a partir de conhecimentos adquiridos e desenvolvidos nesse estado; tamanho das unidades produtivas dessa região; nível de interdependências das firmas e no spillover do conhecimento (que tende a facilitar os fluxos de informações, resultando na formação de redes produtivas e de inovação); integração da economia paranaense com o mercado internacional; análise histórica e social do estado que fundamentam padrões e estruturas econômicas atuais (path dependence); e, por fim, nas relações tácitas entre os trabalhadores e dirigentes das firmas.

\section{Considerações finais}

A teoria utilizada neste artigo aponta que o aspecto regional é fundamental para se compreender a dinâmica da inovação. Esta é, assim, influenciada pelos agentes restritos à determinada área econômica, a qual contém uma infraestrutura institucional particular. Muito mais, a história, a política, as instituições, a cultura, a educação e a geografia de uma região influenciam o SI. Esses diversos elementos compõem várias áreas das ciências sociais e não são todos analisados neste trabalho, dado o espaço limitado deste artigo. Porém, através desse arcabouço teórico, se interpretaram as informações reunidas sobre o SRI paranaense.

A análise das características do processo de inovação das empresas do PR realizada neste artigo revelou parte das falhas do sistema de inovações do Paraná. Tais falhas incluem, resumidamente, o baixo dinamismo na relação entre Institutos de Ciência e Tecnologia e empresas; a quase inexistência de financiamento privado para atividades de inovação; e a insuficiente transferência de pesquisadores pós-graduados das universidades para as firmas.

Verificou-se também que as políticas de inovação devem ser formuladas embasadas em informações que retratem a situação do SI. As falhas constatadas neste trabalho devem ser levadas em consideração no momento de definição, implementação e avaliação de políticas de inovação no PR, assim como para a elaboração de estratégias empresariais. Como lembram Metcalfe e Gorghiou (1997), a política deve ser elaborada conforme a situação específica vivenciada pelas firmas inovadoras e pelo conjunto do SI.

Os aspectos do SRI do Paraná, analisados neste artigo, são elementares no processo de inovação das firmas, porém não são as únicas variáveis que embasam a formulação de políticas, como já reconhecido anteriormente. 
Portanto, alguns passos importantes para o aprimoramento das políticas de inovação no Paraná são: primeiro, continuar identificando os detalhes do SI do Paraná; segundo, comparar o SRI do Paraná com outros; e terceiro, avaliar as políticas de inovação do Estado.

\section{Referências}

Albagli, S.; Britto, J. (2011). "Glossário de arranjos produtivos locais." Relatório de Pesquisa, Rio de Janeiro, UFRJ, s/n, ago. 2002. URL [on-line]: <http://www. ie.ufrj.br/redesist> Acesso em: 23 jul. 2011.

Breschi, S.; Malerba, F. (1997). "Sectorial Innovation Systems: Technological Regimes, Schumpeterian Dynamics and Spatial Boundaries." In: EDQUIST, C. (ed.). Systems of Innovations. London / Washington: Pinter.

Calzolaio, A. E.; Zen, A.; Dathein, R. (2012). "Política de Inovação do RS: uma contribuição a partir da análise das empresas inovadoras e suas relações com o Sistema de Inovação.” Sexto Encontro de Economia Gaúcha. Porto Alegre.

Carvalho, L. P. M. (2010). “Apresentação.” In: Nova geração de política em ciência, tecnologia e inovação: Seminário Internacional. Brasília: Centro de Gestão e Estudos Estratégicos.

Cassiolato, J. E. (1999). "A economia do conhecimento e as novas políticas industriais e tecnológicas.” In: LASTRES, H. M. M.; ALBAGLI, S. (orgs.). Informação e globalização na era do conhecimento. Rio de Janeiro: Campus.

Chesnais, F. (2010). "National systems of innovation, foreign direct investment and the operations of multinational enterprises." In: LUNDVALL, B-Å. (ed.). National Systems of Innovation: toward a theory of innovation and interactive learning. London: Anthem Press.

Cooke, P. (2001). Regional innovation systems, clusters, and the knowledge economy. Industrial and Corporate Change, Oxford, v. 10, n. 4, p.945-974.

Czarnitzki, D.; Hanel, P.; Rosa, J. M. (2010). Evaluating the Impact of R\&D Tax Credits on Innovation: A Microeconometric Study on Canadian Firms. ZEW Discussion Paper, n. 04-77, nov. 2004. URL [on-line]: <ftp://ftp.zew.de/pub/zewdocs/dp/dp0477.pdf>. Acesso em: 01_nov. 2010.

Doloreux. D.; Parto, S. Regional Innovation Systems: A Critical Review. URL [online]: <http://www.ulb.ac.be/soco/asrdlf/documents/RIS_Doloreux-Parto_000.pdf>. Acesso em: 11 jul. 2012.

Edquist, C.; Johnson, B. (1997). "Institutions and organisations in systems of innovation." In: . (eds.). Systems of Innovation: technologies, institutions and organizations. London / Washington: Pinter / Cassell Academic.

Edquist, C.; Johnson, B. (2001). "Innovation Policy - A Systemic Approach." In: Archibugi, D.; Lundvall, B. A. (eds.). The Globalizing Learning Economy. Oxford: Oxford University Press.

Edquist, C.; Johnson, B. (2004). "Systems of Innovation - A Critical Review of The State of the Art." In: Faberberg, J.; Mowery, D.; Nelson, R. Handbook of Innovation. Oxford: Oxford University Press, 2004. 
Freeman, C. (1995). "The National System of innovation in historical perspective." Cambridge Journal of Economics, Cambridge, v. 19 (1), n. 1, p. 5-24.

Hall, B. H. (1995). "Effectiveness of Research and Experimentation Tax Credits: Critical Literature Review and Research Design. Report prepared for the Office of Technology Assessment." Congress of the United States.

Hodgson, G. M. (2004). "What are institutions?” Journal of Economic Issues, v. XL, n. 1, p. 1-25.

IBGE (Instituto Brasileiro de Geografia e Estatísitca). (2010). Pesquisa Industrial de Inovação Tecnológica 2008. Rio de Janeiro, 158 p, 2010. URL [on-line]: <http:// www.ibge.gov.br/home/estatistica/economia/industria/pintec/2008/ pintec2008. pdf>. Acesso em 20 jan. 2010.

Kubota, L. C.; Negri, J. A. (eds.). (2008). Políticas de Incentivo à Inovação Tecnológica no Brasil. Brasília: IPEA.

Luna, F.; Moreira, S.; Gonçalves, A. (2008). "Financiamento à inovação.” In: Kubota, L. C.; Negri, J. A. (eds.). Políticas de Incentivo à Inovação Tecnológica no Brasil. Brasília: IPEA, 2008.

Lundvall, B. A. (2003). "National innovation systems: History and Theory, Contribution to be published." In: Elgar Companion to Neo-Schumpeterian Economics. Cheltenham: Edward Elgar Publishing Limited.

Lundvall, B. A. (2010). National Systems of Innovation: toward a theory of innovation and interactive learning. London: Anthem Press.

Metcalfe, J. S.; Gorghiou, L. (1997). Equilibrium and Evolutionary Foundations of Technology Policy. CRIC Discussion Paper. Manchester: Centre for Research on Innovation and Competition.

Narula, R.; Zanfei, A. (2005). "Globalization of innovation: the role of multinational enterprises.” In: Fagerberg, J.; Mowery, D. C.; Nelson, R. R. (eds.). The Oxford Handbook of Innovation. Oxford: Oxford University Press.

Narula, R.; Dunning, J. H. (2009). Multinational enterprises, development and globalisation: Some clarifications and a research agenda. United Nations University.

Negri, J.; Freitas, F.; Costa, G.; Silva, A.; Alves, P. (2005). Tipologia das Firmas Integrantes da Indústria Brasileira: Procedimentos Metodológicos Utilizados no Projeto de Pesquisa "Inovação, Padrões Tecnológicos e Desempenho das Firmas Industriais Brasileiras”. Brasília.

Nelson, R. R.; Winter, S. G. (1982). An Evolutionary Theory of Economic Change. Cambridge: Harvard University Press.

North, D. C. Institutions. (1991). Journal of Economic Perspectives. American Economic association v. 5, n. 1, p. 97-112.

Nyholm, J.; Normann, L.; Petersen, C. F.; Riis, M.; Tortensen, P. (2001). "Innovation policy in the knowledge-based economy - can theory guide policy making?" In: Archibugi, D.; Lundvall, B. A. (eds.). The Globalizing Learning Economy. Oxford University Press.

Schumpeter, J. A. (1982). Teoria do Desenvolvimento Econômico. São Paulo: Abril Cultural (Coleção Os Economistas). 
Suzigan, W.; Villela, A. (1997). Industrial Policy in Brazil. Campinas: IE/Unicamp.

Tödtling, F; Trippl, T. (2005). "One size fits all? Towards a differentiated regional innovation systems." Research Policy, vol. 34(8).

Velho, L. M. L. S. (2010). "Política científica, tecnológica e de inovação baseada em evidência: a "velha" e a "nova" geração." In: Nova geração de política em ciência, tecnologia e inovação. Seminário Internacional. Brasília: Centro de Gestão e Estudos Estratégicos. 